\title{
A POLÍTICA DE PROMOÇÃO AOS DIREITOS HUMANOS NO GOVERNO LULA
}

Rodrigo Stumpf González

\begin{abstract}
Resumo
Com a eleição de Lula em 2002, o Partido dos Trabalhadores chegou ao poder, pouco mais de duas décadas depois de sua criação. Tendo em vista as propostas deste partido, defendidas no passado, criou-se uma expectativa sobre as mudanças que ocorreriam nas políticas governamentais com relação aos governos anteriores. Um dos campos em que eram esperadas alterações era o referente ao atendimento aos direitos humanos em seus diversos aspectos. Passados oito anos, este texto busca fazer um balanço deste período, avaliando os documentos oficiais e as iniciativas governamentais realizadas.
\end{abstract}

Palavras-chave: Direitos Humanos; Governo Federal; Lula; Políticas Públicas; Direitos Civis.

\begin{abstract}
When Lula was elected in 2002, The Workers Party came to power, two decades after its creation. Taking the proposals of the party in the past, changing in public policies regarding previous governments were expected. One of the fields where changes were expected was that concerning human rights. Now passed eight years, this text made a balance of the period, evaluating official documents and governmental initiatives implemented.
\end{abstract}

Keywords: Human Rights; Federal Government; Lula; Public Policies; Civil Rights.

\section{Introdução}

O tema dos direitos humanos é costumeiramente apropriado pela área do direito e da filosofia política e tratado de forma normativa, em termos de dever ser. A contraposição entre concepções abstratas e universalizantes contra as restritas e pragmáticas em relação aos direitos humanos pode ser encontrada já no processo da formulação do conceito, nas obras de autores como Rousseau (1989), Burke (1984) e Bentham (1962) (ver, por exemplo, o Contrato Social e o Discurso sobre a origem e o fundamento da desigualdade entre os homens, de Rousseau, as Reflexões sobre a revolução na França, de Burke e Anarchical Fallacies, de Bentham) e na diferença entre o Bill of Rights oriundo da Revolução Gloriosa de 1688 e a Declaração de Direitos do Homem e do Cidadão francesa de 1789. 
A linguagem dos direitos humanos pós II Guerra Mundial e muitos dos documentos internacionais produzidos neste período parecem aproximar-se mais da versão francesa do que da britânica. A Declaração Universal dos Direitos Humanos de 1948 e vários dos pactos internacionais da ONU (Organização das Nações Unidas), como os de Direitos Civis e Políticos e dos Direitos Econômicos Sociais e Culturais, propõem direitos universais, sem, no entanto, garantir instrumentos diretos de sua concretização. Seu domínio, o do direito internacional (frequentemente adjetivado de soft), é bastante permeável à discussão de princípios filosóficos e à retórica (GONZÁLEZ, 2007).

Mesmo quando os princípios internacionais foram incorporados às constituições nacionais, sua validade empírica foi colocada à prova, por interpretações baseadas em conceitos como o de norma programática ou de reserva do possível.

No entanto, como obrigação governamental, o atendimento aos direitos humanos pode ser analisado em termos das ações planejadas e executadas com o objetivo de colocar em prática os princípios e regras propostas pelas declarações, tratados e constituição federal, como políticas públicas para os direitos humanos.

Conforme a definição singela de Thomas Dye (1987), as políticas públicas são qualquer coisa que o governo decide fazer ou não fazer. 0 autor chama a atenção para o fato de que a decisão de não realizar algo pode ser tão importante como a do que foi feito.

As políticas públicas que introduzem modificações no perfil de desigualdade social tendem a ser denominadas de políticas sociais e em geral não foram associadas a uma totalidade orgânica do conceito de direitos humanos, salvo como forma retórica de justificar uma reivindicação específica, mas o fruto de lutas e conquistas específicas para a melhoria das condições de vida, em campos como saúde, educação e habitação.

Porém, uma nova perspectiva da relação entre direitos humanos foi construída se tomarmos como marco a Conferência Mundial sobre os Direitos Humanos, de 1993 e o documento resultante, a Declaração de Viena. Neste documento é reconhecida a universalidade e a 
indivisibilidade dos direitos humanos. Ainda que esta afirmação também tenha um conteúdo retórico, neste documento também é proposto que os países signatários devam criar planos nacionais para por em prática o disposto nos documentos e tratados internacionais - item $71 \mathrm{da}$ Declaração (ONU, 1993).

Dentro deste marco, pode-se falar na construção de uma articulação, neste plano de ação, do conjunto de ações para a proteção e promoção dos direitos humanos como uma política nacional para os direitos humanos. Com base nestas considerações, o conjunto de ações para a proteção e promoção de direitos humanos em um determinado governo pode ser considerado e analisado como uma política pública, ainda que tal articulação entre as ações não tenha sido assumida como tal pelos próprios governantes.

A eleição de Lula em 2002 criou expectativas em relação às mudanças que ocorreriam em relação aos governos anteriores. Este trabalho busca analisar como o tema dos direitos humanos foi tratado do ponto de vista institucional nos dois mandatos do Presidente Luis Inácio Lula da Silva, entre 2003 e 2010. Foram produzidas diferentes análises de como o tema foi tratado durante os governos do Presidente Fernando Henrique Cardoso (PINHEIRO e MESQUITA NETO, 1997; MESQUITA NETO, 1999; OLIVEIRA, 2000; GONZÁLEZ, 2008). No entanto, os dois governos de Lula ainda carecem de um balanço analítico mais aprofundado neste campo.

Para isso são reconstruídos o caminho histórico desenvolvido pelo país em relação ao reconhecimento de direitos humanos e seus vínculos com o sistema internacional no período recente. São identificadas as bases anteriores da política de direitos humanos com uma discussão do I e II Programas Nacionais de Direitos Humanos.

Em seguida serão analisadas as principais políticas do Governo Lula, em seus dois mandatos, com relação aos direitos humanos, buscando verificar a existência e conteúdo de uma política pública nacional para a promoção de direitos humanos. Finaliza-se se avaliando quais as perspectivas para os direitos humanos no país para o futuro. 


\section{A evolução histórica do reconhecimento dos direitos humanos no Brasil}

Do ponto de vista formal, o Brasil muito cedo incorporou dispositivos de reconhecimento e proteção aos direitos humanos a sua ordem jurídica. No entanto, a aplicação destes dispositivos nem sempre foi completa ou para toda a população, seja nos períodos autoritários, seja nos formalmente democráticos. Porém, o período de maior distanciamento em relação ao cumprimento dos preceitos mínimos de direitos humanos foi o da ditadura militar de 1964 a 1985.

Com as limitações impostas pelo regime à imprensa e à ação dos advogados, a denúncia de violações no exterior e ação interna de líderes religiosos, como Dom Hélder Câmara e Dom Paulo Evaristo Arns tornouse a resposta possível (GONZÁLEZ, 1994).

No período de transição, com a distensão proposta pelo General Ernesto Geisel aumenta a capacidade de pressão e mobilização da sociedade, com a ação de organizações como a ABI (Associação Brasileira de Imprensa) e a OAB (Ordem dos Advogados do Brasil) lutando pela redemocratização (GONZÁLEZ, 2005).

$\mathrm{Na}$ década de 70 surgiram diversos movimentos em defesa dos presos políticos, dos desaparecidos e na luta pela anistia, alguns dos quais se tornaram organizações não governamentais que contribuíram para a criação, em 1982, do Movimento Nacional de Direitos Humanos (MESQUITA NETO, 1999).

Nos dois primeiros governos pós-constituinte, compostos pelo mandato de Fernando Collor de Mello de 1990 a 1992, completado por seu vice, Itamar Franco, de 1993 a 1994, não se identifica uma política específica destinada aos direitos humanos, mas o Brasil começa um processo de reaproximação com os sistemas internacionais de proteção aos direitos humanos, voltando a integrar a comunidade internacional como membro pleno.

Da redemocratização em 1946 até o golpe militar de 1964, o Brasil participou do processo de definição dos documentos internacionais de direitos humanos, aderindo à maioria dos textos aprovados. Destacam-se, ainda na década de 40, a Declaração de Direitos e 
Deveres do Homem, da OEA (Organização dos Estados Americanos), aprovada em 1947 e a Declaração Universal dos Direitos Humanos, da ONU, em 1948.

O golpe militar levou a um afastamento do país em relação às normativas internacionais de proteção aos direitos humanos.

Neste período houve uma série de avanços na normativa internacional. Em 1966 a ONU aprovou o Pacto de Direitos Civis e Políticos e o Pacto de Direitos Econômicos, Sociais e Culturais. Em 1969 a OEA aprovou a Convenção Americana de Direitos Humanos, o Pacto de San José. Estes documentos somente foram subscritos pelo Brasil depois do retorno à democracia.

A última década do século XX marcou a reconciliação do Brasil com o sistema internacional de proteção aos direitos humanos. Neste período não só foram subscritos e ratificados pelo país os principais pactos como este buscou um papel de protagonismo mais ativo nos espaços internacionais.

Foram ratificados em 1992 o Pacto de Direitos Civis e Políticos e o Pacto de Direitos Econômicos, Sociais e Culturais, da ONU. Neste mesmo ano também foi ratificada a Convenção Americana de Direitos Humanos.

Entre outras convenções cabe também destacar a adesão do Brasil à Convenção da ONU sobre Direitos da Criança e as Convenções 138 e 182 da OIT (Organização Internacional do Trabalho), sobre o trabalho infantil.

O protagonismo brasileiro foi reforçado pela realização, na cidade do Rio de Janeiro, da Conferência das Nações Unidas sobre Meio Ambiente e Desenvolvimento, a Rio 92. No ano seguinte a representação do Brasil ocupou um papel importante no processo de redação da declaração final da II Conferência Mundial de Direitos Humanos, da ONU, realizada em Viena (CANÇADO TRINDADE, 1997).

À adesão às normas dos sistemas internacionais foram acrescidas a aceitação da competência da Corte Interamericana de Direitos Humanos, em 1998, e a adesão ao Tratado de Roma, que criou o Tribunal Penal Internacional, em 2000. 
Se a Constituição de 1988 foi a base para uma perspectiva sobre os direitos humanos no Brasil, a criação de vínculos com os sistemas internacionais de proteção demonstraria uma política de transparência das ações governamentais, que não precisariam mais se esconder sob o argumento da soberania nacional. A construção de uma política articulada neste sentido começa a ser construída no governo do Fernando Henrique Cardoso.

Aprofundando algumas ações realizadas nos governos anteriores, particularmente na adesão a tratados internacionais, durante os mandatos do Presidente Fernando Henrique Cardoso começa a se desenhar uma política para os direitos humanos no Brasil.

Algumas medidas foram tomadas por iniciativa governamental, porém outras são resultado da mobilização da sociedade. Fora do espaço do Poder Executivo cabem dois destaques: a criação da Comissão de Direitos Humanos da Câmara dos Deputados e a realização das Conferências Nacionais de Direitos Humanos.

No Congresso Nacional foi criada em 1995 a Comissão de Direitos Humanos da Câmara dos Deputados, iniciativa seguida por diversas Assembléias Legislativas. A atuação da Comissão da Câmara tem sido relevante em ações como a articulação de Comissões Parlamentares de Inquérito e avaliação de projetos em tramitação, como o bloqueio, por anos, das propostas de emenda constitucional que buscavam reduzir a idade mínima de imputabilidade penal.

Uma das atividades realizadas pela Comissão, denominada Caravanas dos Direitos Humanos, levou à formulação de relatórios sobre a situação em todo o país de áreas sensíveis na violação de direitos humanos, como prisões, hospitais psiquiátricos e estabelecimentos de internação de adolescentes.

Contando com o apoio da Comissão da Câmara dos Deputados, realizou-se no espaço do Congresso Nacional a I Conferência Nacional de Direitos Humanos, em 1996, mobilizando organizações de defesa dos direitos humanos de todo o país.

A partir de então ocorreram conferências periódicas, com uma progressiva participação do Poder Executivo. Foram realizadas 
Conferências Nacionais de Direitos Humanos em 1996, 1997, 1998, 1999, 2000, 2001, 2002, 2003, 2005 e 2006, sendo a última a XI Conferência, realizada em 2008. As conferências têm servido de espaço de avaliação das políticas realizadas e de pressão às autoridades públicas.

A preocupação do Governo Federal como o tema começa a se desenhar em 1995, quando foi criado o Prêmio Nacional de Direitos Humanos, para dar maior visibilidade a pessoas e instituições que atuavam na defesa e promoção de direitos.

Neste mesmo ano começa a ser enfrentado um dos temas do passado ditatorial ainda sem solução. A lei de anistia de 1979 serviu de pretexto para bloquear investigações sobre mortos e desaparecidos durante a ditadura. Com a aprovação da Lei 9.140/95 o governo reconheceu uma lista de pessoas como tendo sido mortas por ação do Estado, garantindo indenizações a seus familiares, bem como aos sobreviventes que foram vítimas de tortura (GONZÁLEZ, 2002). A lei sofreu modificações, ampliando o período previsto para os atos de violação de 1979 para 5 de outubro de 1988. A comissão que analisa os casos continua em funcionamento até a atualidade.

A ação mais concreta, no entanto, para conformar uma política destinada aos direitos humanos, no período, foi a proposição do Programa Nacional de Direitos Humanos. Procurando cumprir as diretrizes propostas pela Conferência de Viena, de 1993, como parte dos compromissos assumidos, o Presidente Fernando Henrique Cardoso criou uma comissão para elaborar um plano nacional de direitos humanos. Sob a coordenação de José Gregori, a construção do projeto do plano foi organizada pelo Núcleo de Estudos da Violência (NEV), da Universidade de São Paulo (USP), à época coordenado por Paulo Sérgio Pinheiro (MESQUITA NETO, 1999).

Após a realização de uma série de seminários de discussão, com a participação de representantes de diferentes segmentos sociais, foi lançado pelo Presidente Fernando Henrique Cardoso em 13 de maio de 1996 o Programa Nacional de Direitos Humanos - PNDH. Segundo sua apresentação: 


\title{
DOSSIÊ OS ANOS LULA
}

O objetivo do Programa Nacional de Direitos Humanos (PNDH), elaborado pelo Ministério da Justiça em conjunto com diversas organizações da sociedade civil, é, identificando os principais obstáculos à promoção e proteção dos direitos humanos no Brasil, eleger prioridades e apresentar propostas concretas de caráter administrativo, legislativo e político-cultural que busquem equacionar os mais graves problemas que hoje impossibilitam ou dificultam a sua plena realização. O PNDH é resultante de um longo e muitas vezes penoso processo de democratização da Sociedade e do Estado brasileiro (Decreto 1.904/96 - I PNDH).

O I PNDH foi dividido em sete títulos gerais e vinte subtítulos. Cada um deles apresenta um conjunto de objetivos, definidos segundo o prazo de implantação. São 9 objetivos permanentes, 150 de curto prazo, 55 de médio prazo e 14 de longo prazo, totalizando 228 objetivos propostos.

Conforme reconheceu a própria introdução do texto do programa, os objetivos concentram-se no atendimento a direitos individuais que podem ser enquadrados nas categorias de direitos civis. Segundo o texto:

\begin{abstract}
O Programa, apesar de inserir-se dentro dos princípios definidos pelo Pacto Internacional de Direitos Civis e Políticos, contempla um largo elenco de medidas na área de direitos civis que terão conseqüências decisivas para a efetiva proteção dos direitos sociais, econômicos e culturais como, por exemplo, a implementação das convenções internacionais dos direitos das crianças, das mulheres e dos trabalhadores (I PNDH).
\end{abstract}

O entendimento de que é prioritário dar atenção aos direitos civis, sem descartar a importância dos direitos sociais, parte de uma avaliação de que este é o fundamento necessário para outras mudanças. Completa o texto:

Mas, para que a população possa assumir que os direitos humanos são direitos de todos, e as entidades da sociedade civil possam lutar por esses direitos e organizar-se para atuar em parceria com o Estado, é fundamental que seus direitos civis elementares sejam 
garantidos e, especialmente, que a Justiça seja uma instituição garantidora e acessível para qualquer um (I PNDH).

Esta avaliação foi corroborada na avaliação feita no ano seguinte por dois dos responsáveis pela elaboração do texto (PINHEIRO e MESQUITA NETO, 1997). O déficit histórico do reconhecimento de direitos individuais no Brasil seria um dos elementos que impede a construção de uma cultura de respeito aos direitos humanos e contribui para a prática sistemática de violações, em especial por agentes do Estado.

Além de uma opção consciente de privilegiar os direitos civis, um outro fator contribuiu para esta limitação. As ações propostas no Programa fazem parte das atribuições do Ministério da Justiça, de onde partiu a iniciativa.

As avaliações do I PNDH são contraditórias. De um lado, há autores, como Mesquita Neto (1999), que destacam os avanços conquistados e as mudanças institucionais que foram obtidas no período. Por outro lado, Oliveira (2000), embora reconheça a sua contribuição, critica as limitações do programa na promoção de direitos civis.

A partir de 1999 se iniciou o processo de discussão para revisão do texto do I PNDH. Foram realizados diversos eventos, novamente sob coordenação do NEV/USP. O projeto do novo texto foi debatido na $V$ Conferência Nacional de Direitos Humanos, em 2000. O texto final foi lançado em maio de 2002 (Decreto 4.229/02. II Programa Nacional de Direitos Humanos).

Em relação ao texto do I PNDH foram propostas diversas mudanças. A principal é a ampliação do escopo do programa, com a inclusão de objetivos que contemplavam também direitos sociais, econômicos e culturais, ao lado de direitos civis e políticos.

Também foi proposta uma mudança de concepção no programa. O texto anexo deixa de ser considerado o programa em si e passa a ser um plano anual, com os objetivos a serem buscados no período de um ano, devendo ser revisado anualmente. Esta revisão, no entanto, não foi 
realizada, passando, na prática, a ser tratado o plano de ação incluído como anexo do decreto de 2002, como II PNDH até a aprovação do III PNDH.

O II PNDH continha 518 objetivos, divididos em 15 títulos e 16 subtítulos. Foram incluídos objetivos referentes a campos de políticas sociais, como saúde, educação, trabalho e moradia.

Por outro lado, também há indicativos de uma mudança de concepção de direitos humanos. O I PNDH, ao estar centrado nos direitos civis, apontava para a adesão a uma concepção universalista de direitos humanos, fundada em valores construídos pelas revoluções liberais do século XVIII e incorporada a documentos da ONU, como a Declaração Universal de Direitos Humanos.

O II PNDH, ao dar atenção a questões como o meio ambiente e à defesa de direito à identidade de grupos sociais específicos, por motivos étnicos, como os afrodescendentes, indígenas e ciganos, ou por motivos culturais, como as diferenças de orientação sexual, abre espaço para as concepções de direitos humanos baseadas na defesa do multiculturalismo e na crítica do antropocentrismo da visão liberal clássica.

Tendo sido aprovado no final do mandato de Fernando Henrique Cardoso, em tese, o II PNDH deveria ter sido o principal balizador das políticas de direitos humanos no período seguinte, em que se iniciou o Governo Lula.

\section{A Política de Direitos Humanos no Governo Lula}

A eleição de 2002 foi marcada pelo debate sobre as possíveis mudanças que poderiam ocorrer na eventualidade da escolha do candidato do PT (Partidos dos Trabalhadores), Lula. Um líder com passado operário e as origens de esquerda do partido, criado de um estranho amálgama de líderes sindicais, movimentos sociais católicos e grupos de esquerda de origem trotskista levaram seus adversários na eleição a explorar a desconfiança sobre um futuro desconhecido em propagandas eleitorais em que uma conhecida atriz de televisão declarava "Eu tenho medo!". 
Para afastar este medo foi lançada a Carta ao Povo Brasileiro (SILVA, 2002), assinada por Lula e destinada primordialmente a apaziguar o ânimo dos investidores internacionais. Porém a garantia de respeito aos contratos vigentes e a promessa de mudanças graduais e sem sustos não dava indicativos claros dos rumos do novo governo em outras áreas, contando-se apenas com a possível continuidade de experiências de administrações petistas em nível municipal e estadual.

A ênfase principal nos dois mandatos do Presidente Lula, em relação aos direitos humanos, parece ter se dado no combate à pobreza extrema, com políticas sociais de combate à fome e distribuição de renda. Seus símbolos são os Programas Fome Zero e Bolsa Família. Porém, também foi direcionada atenção a grupos sociais específicos, como os negros e as mulheres. No entanto, estas ações geralmente não foram executadas com um discurso articulado em nome dos direitos humanos, denominação que ficou em geral restrita às atividades vinculadas à Secretaria Especial de Direitos Humanos da Presidência da República e ao Ministério da Justiça.

A seguir é analisada a evolução da estrutura institucional dos órgãos destinados a algumas das políticas específicas de promoção aos direitos humanos desde 2003, bem como do Programa Nacional de Direitos Humanos neste período.

\section{Direitos humanos e ministérios no Governo Lula}

Com o início do novo governo foram criados novos órgãos com status ministerial, ou alterada a estrutura dos pré-existentes, para a promoção de diversos campos dos direitos humanos. Ao longo dos dois mandatos alguns deles se mantiveram, outros foram extintos ou incorporados a outros ministérios.

A Secretaria de Estado dos Direitos da Mulher do Ministério da Justiça, foi criada pela Medida Provisória 37, de 8 de maio de 2002, convertida na lei 10.539, de 23 de setembro de 2002, ainda pelo Governo Fernando Henrique Cardoso. Posteriormente, em 2003 foi transformada em Secretaria Especial de Políticas para as Mulheres, na mesma medida provisória que criou a Secretaria Especial de Direitos 
Humanos e o Gabinete do Ministro de Estado Extraordinário de Segurança Alimentar e Combate à Fome, todos vinculados à Presidência da República, com ocupantes com status de Ministro (MP 103/03).

Pouco após foi criada a Secretaria Especial de Políticas de Promoção da Igualdade Racial, pela MP 111/03, convertida na lei 10.678/03, também junto à Presidência da República e com status de ministro para seu ocupante.

É interessante observar que as Secretarias Especiais de Políticas para as Mulheres e de Promoção da Igualdade Racial não sofreram alterações com a reforma ministerial de 2005, quando foi extinta, por quatro meses, a Secretaria Especial dos Direitos Humanos. Por outro lado, ao longo do Governo Lula foram criadas e extintas secretarias especiais junto à Presidência, como a de Aqüicultura e Pesca e a de Portos e a do Conselho de Desenvolvimento Econômico e Social e Gabinete do Ministro Extraordinário de Segurança Alimentar e Nutricional, cujas funções passaram para o Ministério do Desenvolvimento Social com a extinção do cargo.

Estas secretarias foram em geral utilizadas para acomodar os interesses partidários nas reformas ministeriais. Com estruturas leves, contando com poucos funcionários, concediam ao ocupante o status de ministro, a possibilidade de atuação política, mas sem o ônus político e econômico da criação de um novo ministério.

Um dos exemplos de superposição entre as competências das Secretarias está nos conselhos ligados a elas. A Secretaria Especial de Políticas de Promoção da Igualdade Racial conta como parte de sua estrutura básica com o Conselho Nacional de Promoção da Igualdade Racial - CNPIR, criado junto com a secretaria em 2003. Tratando de temas semelhantes o Conselho Nacional de Combate à Discriminação CNCD foi criado em 2001, vinculado à Secretaria de Estados dos Direitos Humanos do Ministério da Justiça, passando posteriormente a compor a Secretaria Especial de Direitos Humanos. Sua composição foi mudada em 2005, sem, no entanto, terem sido alterados seus objetivos. As finalidades destes conselhos são bastante semelhantes, conforme pode se ver nos decretos $4.885 / 03$ e 5.397/05. 
A fragmentação pode ser explicada por uma concepção de direitos humanos que valoriza o direito à diferença e à identidade, mas também pode ser devida ao particularismo dos interesses envolvidos, tanto em termos de exploração política da visibilidade dos cargos como dos grupos sociais cuja mobilização justificou a criação do organismo.

O interesse do Presidente da República parece também ser fundamental na definição da estrutura institucional a qual forma determinadas políticas.

O Programa Fome Zero foi criado no inicio do primeiro governo Lula (MP 103, de 01 de janeiro de 2003). Do ponto de vista institucional estava vinculado ao recém-criado Gabinete do Ministro de Estado Extraordinário de Segurança Alimentar e Combate à Fome, um ministro sem ministério vinculado diretamente à Presidência da República.

Outro programa importante no Governo Lula, o Bolsa-Família, surgiu da unificação das ações de transferência de renda do Governo Federal, como as do Programa Nacional de Renda Mínima vinculado à Educação - Bolsa Escola, do Programa Nacional de Acesso à Alimentação - PNAA, do Programa Nacional de Renda Mínima vinculada à Saúde - Bolsa Alimentação e do Programa Auxílio-Gás, já existentes, por meio da MP 132, de 20 de outubro de 2003, ficando vinculado a um conselho gestor ligado também à Presidência da República.

Posteriormente, com a incorporação da Secretaria Executiva do Conselho Gestor Interministerial do Programa Bolsa Família e do Gabinete do Ministro Extraordinário de Segurança Alimentar e Nutricional ao Ministério da Assistência Social, foi criado um novo ministério com a denominação de Ministério do Desenvolvimento Social, pela MP 163, de 23 de janeiro de 2004. Enquanto o Fome Zero parece ter se tornado mais importante nos discursos do Presidente da República no exterior, ao Bolsa Família é atribuída por muitos sua reeleição e grande parte da popularidade que se manteve no segundo mandato.

Com a criação do Programa de Aceleração do Crescimento, o PAC, programas sociais com execução vinculada a financiamento de obras, como são os casos do saneamento básico e da habitação 
passaram a ter na Casa Civil o ministério responsável pela articulação das ações, como no caso do Minha casa, minha vida.

Diante desta diversidade de órgãos responsáveis por políticas que atendem diferentes aspectos dos direitos humanos, é preciso analisar como ficou no período o órgão que traz o nome da política em sua própria denominação.

\section{A Secretaria Especial de Direitos Humanos}

Um dos elementos que permite verificar as idas e vindas da trajetória da política de direitos humanos no Brasil são as mudanças ocorridas no órgão do Governo Federal encarregado em tese do gerenciamento do Programa Nacional de Direitos Humanos.

A Secretaria Nacional dos Direitos Humanos, vinculada ao Ministério da Justiça, foi criada no Governo Fernando Henrique Cardoso pelo Decreto no 2.193, de 7 de abril de 1997. Ela substituiu a Secretaria de Direitos da Cidadania, existente nos governos anteriores, que possuía um departamento de direitos humanos.

Esta mudança é feita para atribui ao novo órgão a competência de

$$
\begin{aligned}
& \text { X - coordenar, gerenciar e acompanhar a execução do } \\
& \text { Programa Nacional de Direitos Humanos- PNDH dando } \\
& \text { coerência às políticas setoriais das diversas áreas } \\
& \text { governamentais em matéria de direitos humanos e } \\
& \text { cidadania, em articulação com a sociedade civil (Inciso } \\
& \text { X do Art. } 8^{\circ} \text { do Decreto no } 1.796 \text {, de } 24 \text { de janeiro de } \\
& 1996 \text {, com a redação dada pelo Decreto } 2.193 / 97 \text { ). }
\end{aligned}
$$

A nova Secretaria foi ocupada por José Gregori, que a deixou para ocupar o cargo de Ministro da Justiça, tendo posteriormente ocupado o cargo Paulo Sérgio Pinheiro. Foi renomeada Secretaria de Estado dos Direitos Humanos.

Com a posse do Governo Lula, o órgão transformou-se na Secretaria Especial dos Direitos Humanos, vinculada à Presidência da República (Medida Provisória 103/03, de 01 de janeiro de 2003, transformada na lei $10.683 / 03$ ). Foi dado ao ocupante do cargo o status de Ministro. Foi nomeado ministro o ex-deputado federal Nilmário 
Miranda, que havia sido presidente de Comissão de Direitos Humanos da Câmara dos Deputados.

Esta mudança significou um aumento de prestígio, tanto para a secretaria como os diversos Conselhos Nacionais a ela ligados, que passaram a compor a estrutura da Presidência da República.

A ação do órgão interno de um ministério normalmente é vista como uma invasão indevida, ao tentar interferir em atividades de outro ministério, ainda que no cumprimento de competências legais, pois o ato tende a ser interpretado como ingerência de um escalão inferior em decisões que deveriam ser submetidas ao ministro de cada pasta, ainda mais em um governo de coalizão de diferentes partidos. Tal situação não se configura quando se trata da Presidência da República, que estaria acima de todos os ministérios.

Em 2005, ao realizar uma reforma ministerial devido à exoneração de ministros que concorreriam às eleições naquele ano, foram anunciadas pelo Porta-Voz da Presidência da República a saída do Ministro Nilmário Miranda e a extinção de seu cargo, com o retorno da Secretaria ao Ministério da Justiça (SINGER, 2005).

$\mathrm{Na}$ verdade, a medida acabou sendo modificada, quando emitida a medida provisória 259/05, conforme seu art. 2ํ "São transferidas as competências: IV - da Secretaria Especial dos Direitos Humanos da Presidência da República, para a Secretaria-Geral da Presidência da República". Mesmo rebaixada de seu status ministerial, continuou a estar vinculada à Presidência da República como uma subsecretaria da Secretaria Geral da Presidência. Com a saída de Nilmário Miranda, passou a ser ocupada por Mario Mamede.

O fato gerou inúmeros protestos, tanto de representantes de organizações não governamentais de defesa dos direitos humanos como da Comissão de Direitos Humanos da Câmara dos Deputados (INESC, 2005).

Uma emenda na Câmara dos Deputados, no projeto de conversão da medida provisória em lei alterou o artigo, restituindo a Secretaria à situação anterior. O Presidente da República sancionou a Lei 11.204 de 5 de dezembro de 2005 com a alteração. O Secretário Mário Mamede, 
que ocupou o cargo desde julho tornou-se ministro interino por cerca de uma semana, até a nomeação de Paulo de Tarso Vannuchi como novo ministro, que se manteve até o final do segundo mandato.

Neste período a SEDH (Secretaria Especial dos Direitos Humanos) ampliou seu orçamento, principalmente com os gastos com a indenização de vítimas e familiares do regime militar e seu quadro de pessoal, mas continuou funcionando em espaços do Ministério da Justiça (BRASIL, 2006, 2007a, 2008a, 2008b, 2009a, 2009b). Esta dependência pode ser inclusive detectada pelo uso do domínio daquele ministério, até 2009 para divulgação de atividades do órgão. Neste período documentos do órgão podia ser acessados no endereço <http://portal.mj.gov.br/sedh/>, passando posteriormente a usar os domínios <http://www.sedh.gov.br/> e $<$ http://www.direitoshumanos.gov.br>.

Embora praticamente durante todo o período do governo Lula o II PNDH estivesse vigente, com execução sob a responsabilidade da SEDH, a criação e execução do Plano Nacional de Educação em Direitos Humanos - PNDEH recebeu uma atenção e divulgação maior que o PNDH no período.

O Plano Nacional de Educação em Direitos Humanos - PNEDH começou a ser elaborado em 2003, com a formação de um comitê com representação da sociedade civil, da Secretaria Especial de Direitos Humanos, do Ministério da Justiça e do Ministério da Educação (BRASIL, 2007b).

Este comitê produziu uma primeira versão do PNEDH em dezembro de 2003. O documento passou a ser debatido em todo o país, recebendo sugestões de alteração. O documento definitivo foi apresentado em dezembro de 2006.

O plano prevê um conjunto de ações direcionadas a diversos segmentos: educação básica, educação superior, educação não-formal, educação dos profissionais dos sistemas de justiça e segurança e educação e mídia. Segundo a apresentação do plano: 


\begin{abstract}
A implementação do Plano Nacional de Educação em Direitos Humanos visa, sobretudo, difundir a cultura de direitos humanos no país. Essa ação prevê a disseminação de valores solidários, cooperativos e de justiça social, uma vez que o processo de democratização requer o fortalecimento da sociedade civil, a fim de que seja capaz de identificar anseios e demandas, transformando-as em conquistas que só serão efetivadas, de fato, na medida em que forem incorporadas pelo Estado brasileiro como políticas públicas universais (BRASIL, 2007b, p. 18)
\end{abstract}

As motivações da criação do PNEDH podem ser consideradas compatíveis com a formulação inicial do I PNDH, que avaliava a inexistência de uma cultura de direitos humanos no Brasil. No entanto no texto do PNEDH há apenas três referências marginais ao PNDH, citado como antecedente da política de direitos humanos no Brasil, constando ainda que o novo plano deve aprofundar as propostas da educação em direitos humanos existentes no PNDH.

Embora o II PNDH estivesse vigente, não foi feita sua revisão anual, conforme era previsto. Por outro lado, a SEDH nos primeiros anos dedicou grande esforço de articulação na criação do novo plano, dando pouca ênfase e divulgação ao $\mathrm{PNDH}$, até a reformulação deste em $2008 / 2009$.

\title{
III Programa Nacional de Direitos Humanos
}

Em 2008, sob a coordenação da SEDH foi realizado o processo de discussão que culminou com a realização da $11^{\text {a }}$ Conferência Nacional dos Direitos Humanos e a proposição do III PNDH. O modelo adotado para a Conferência segue o padrão de outras conferências de avaliação e proposição de políticas públicas realizadas nas últimas duas décadas, em áreas como saúde, assistência social e infância e juventude, com a escolha de delegados e realização de conferências preparatórias estaduais, dando à conferência, ao menos a aparência, de um caráter deliberativo do documento que constituiria o novo PNDH.

A conferência realizou-sede 15 a 18 de dezembro de 2008 . documento final da conferência foi aprovado como III PNDH, tendo sido 
reconhecido como tal pelo Decreto no 7.037, de 21 de Dezembro de 2009.

O documento do novo plano é mais longo e tem uma estrutura ligeiramente diferente dos anteriores, sendo divido em seis eixos orientadores, 25 diretrizes, 82 objetivos estratégicos e 521 ações programáticas.

Os eixos orientadores e as diretrizes do III PNDH são mais abstratos e amplos do que eram os títulos e subtítulos do II PNDH, embora o número de ações propostas (521) seja semelhante ao número de objetivos do plano anterior (518). Enquanto os títulos do II PNDH se parecem com a estrutura dos direitos previstos na Constituição Federal, os temas dos eixos orientadores e as diretrizes do III PNDH parecem refletir a diversidade e a linguagem dos diversos movimentos sociais e organizações não governamentais que articulam a defesa de diferentes segmentos da sociedade, nos aspectos mais diversos, passando por questões tradicionais do campo de direitos humanos, como combate à violência, liberdade e direitos sociais, a temáticas de desenvolvimento mais recente, como meio ambiente e sexualidade.

Por outro lado, diferentemente dos programas anteriores, cuja aprovação e lançamento passou despercebido pela maior parte da sociedade, com baixo interesse da mídia, o lançamento do novo programa rapidamente gerou polêmica, com ataques dentro e fora do governo, com ampla cobertura nacional.

Os ataques foram direcionados a quatro temas: religião, responsabilidade dos meios de comunicação, conflitos no campo e ditadura militar. Em relação ao primeiro, os protestos foram oriundos principalmente de autoridades da Igreja Católica (CNBB, 2010), contra a proposição de descriminalização do aborto, considerando que atacaria o direito à vida, previsto na Constituição, e contra a proibição de ostentar símbolos religiosos em órgãos públicos federais.

No segundo, as empresas do ramo da comunicação protestaram contra a possibilidade da criação de penas de perda da concessão de rádio ou televisão para casos de programação atentatória aos direitos 
humanos e a criação de um ranking de emissoras em relação a seu comprometimento com os direitos humanos.

No terceiro caso, instituições ligadas ao agro-negócio, como a CNA (Confederação Nacional da Agricultura), bem como o Ministro da Agricultura protestaram contra a criação de exigência de mediação com os ocupantes como medida prévia para concessão de liminar para reintegração de posse de áreas invadidas.

O maior número de reclamações, oriundo de segmentos militares, se referiu a ações relacionadas ao eixo orientador Direito à Memória e à Verdade, que se trata principalmente a violações ocorridas durante a ditadura militar de 1964 a 1985.

Os protestos públicos de igreja, empresas de comunicação, ruralistas e militares foram seguidos de manifestações de organizações de defesa dos direitos humanos em defesa do III PNDH, diante das divisões existentes no governo em relação ao texto.

O resultado final foi um recuo do governo, com a aprovação de alterações, por meio do Decreto 7.177/10 em 7 ações programáticas e a eliminação de duas. Em alguns casos, o sentido original foi totalmente retirado, por exemplo, com a substituição da defesa da legalização do aborto por considerá-lo tema de saúde pública. Em outros, a mudança foi mais cosmética, para atender os brios feridos, como a substituição de referências à ditadura militar e à perseguição política pela citação de violações de direitos ocorrida no período previsto no artigo $8^{\circ}$ do Ato das Disposições Transitórias da Constituição de 1988.

A laicização dos órgãos públicos e o ranking de empresas de comunicação foram simplesmente suprimidos. 
Quadro 1 - Estrutura do III Programa Nacional de Direitos Humanos - 2010

\begin{tabular}{|c|c|}
\hline Eixo Orientador & Diretriz \\
\hline $\begin{array}{l}\text { I Interação Democrática } \\
\text { entre Estado e Sociedade Civil }\end{array}$ & $\begin{array}{l}\text { 1: Interação democrática entre Estado e sociedade } \\
\text { civil como instrumento de fortalecimento da } \\
\text { democracia participativa. } \\
\text { 2: Fortalecimento dos Direitos Humanos como } \\
\text { instrumento transversal das políticas públicas e de } \\
\text { interação democrática. } \\
\text { 3: Integração e ampliação dos sistemas de } \\
\text { informação em Direitos Humanos e construção de } \\
\text { mecanismos de avaliação e monitoramento de sua } \\
\text { efetivação. }\end{array}$ \\
\hline $\begin{array}{l}\text { II: Desenvolvimento e } \text { Direitos } \\
\text { Humanos }\end{array}$ & $\begin{array}{l}\text { 4: Efetivação de modelo de desenvolvimento } \\
\text { sustentável, com inclusão social e econômica, } \\
\text { ambientalmente equilibrado e tecnologicamente } \\
\text { responsável, cultural e regionalmente diverso, } \\
\text { participativo e não discriminatório. } \\
\text { 5: Valorização da pessoa humana como sujeito } \\
\text { central do processo de desenvolvimento. } \\
\text { 6: Promover e proteger os direitos ambientais como } \\
\text { Direitos Humanos, incluindo as gerações futuras } \\
\text { como sujeitos de direitos. }\end{array}$ \\
\hline $\begin{array}{l}\text { III: Universalizar Direitos em um } \\
\text { Contexto de Desigualdades }\end{array}$ & $\begin{array}{l}\text { 7: Garantia dos Direitos Humanos de forma } \\
\text { universal, indivisível e interdependente, assegurando } \\
\text { a cidadania plena. } \\
\text { 8: Promoção dos direitos de crianças e adolescentes } \\
\text { para o seu desenvolvimento integral, de forma não } \\
\text { discriminatória, assegurando seu direito de opinião e } \\
\text { participação. } \\
\text { 9: Combate às desigualdades estruturais. } \\
\text { 10: Garantia da igualdade na diversidade. }\end{array}$ \\
\hline $\begin{array}{l}\text { IV: Segurança Pública, Acesso à } \\
\text { Justiça e Combate à Violência }\end{array}$ & $\begin{array}{l}\text { 11: Democratização e modernização do sistema de } \\
\text { segurança pública. } \\
\text { 12: Transparência e participação popular no sistema } \\
\text { de segurança pública e justiça criminal. } \\
\text { 13: Prevenção da violência e da criminalidade e } \\
\text { profissionalização da investigação de atos } \\
\text { criminosos. } \\
\text { 14: Combate à violência institucional, com ênfase na } \\
\text { erradicação da tortura e na redução da letalidade } \\
\text { policial e carcerária. } \\
\text { 15: Garantia dos direitos das vítimas de crimes e de } \\
\text { proteção das pessoas ameaçadas. } \\
\text { 16: Modernização da política de execução penal, } \\
\text { priorizando a aplicação de penas e medidas } \\
\text { alternativas à privação de liberdade e melhoria do } \\
\text { sistema penitenciário. } \\
\text { 17: Promoção de sistema de justiça mais acessível, } \\
\text { ágil e efetivo, para o conhecimento, a garantia e a } \\
\text { defesa dos direitos. }\end{array}$ \\
\hline $\begin{array}{l}\text { V: Educação e Cultura em Direitos } \\
\text { Humanos }\end{array}$ & $\begin{array}{l}\text { 18: Efetivação das diretrizes e dos princípios da } \\
\text { política nacional de educação em Direitos Humanos } \\
\text { para fortalecer cultura de direitos. } \\
\text { 19: Fortalecimento dos princípios da democracia e } \\
\text { dos Direitos Humanos nos sistemas de educação } \\
\text { básica, nas instituições de ensino superior e nas } \\
\text { instituições formadoras. } \\
\text { 20: Reconhecimento da educação não formal como } \\
\text { espaço de defesa e promoção dos Direitos Humanos. } \\
\text { 21: Promoção da Educação em Direitos Humanos no } \\
\text { serviço público. } \\
\text { 22: Garantia do direito à comunicação democrática e }\end{array}$ \\
\hline
\end{tabular}




\begin{tabular}{|c|c|}
\hline & $\begin{array}{l}\text { ao acesso à informação para a consolidação de uma } \\
\text { cultura em Direitos Humanos. }\end{array}$ \\
\hline VI: Direito à Memória e à Verdade & $\begin{array}{l}\text { 23: Reconhecimento da memória e da verdade como } \\
\text { Direito Humano da cidadania e dever do Estado. } \\
\text { 24: Preservação da memória histórica e a construção } \\
\text { pública da verdade. } \\
\text { 25: Modernização da legislação relacionada com a } \\
\text { promoção do direito à memória e à verdade, } \\
\text { fortalecendo a democracia. }\end{array}$ \\
\hline
\end{tabular}

Fonte: Brasil (2010a).

\section{Os direitos humanos fragmentados}

A inclusão na Declaração da Conferência de Viena de uma referência à indivisibilidade e universalidade dos direitos humanos não impede que o cotidiano da luta pela sua efetivação se dê de forma fragmentada, devido às diferentes perspectivas e movimentos sociais envolvidos.

Seria de se esperar que a aplicação do princípio da indivisibilidade levasse à proposição de mecanismos institucionais de coordenação das diferentes ações e programas destinados à promoção dos direitos humanos.

Por outro lado, uma das tendências da administração das políticas públicas, conforme identificado por Heclo (1978) é a fragmentação e formação de comunidades de interesse. As diferenças de capacidade de articulação e pressão destas comunidades se traduzem, entre outros indicadores, na capacidade de criação de órgãos com relativa independência dentro da administração pública, que sirvam de canal de contato e articulação dos interesses sociais de uma determinada área ou grupo.

O fator cultural também é importante. No Brasil foram mais facilmente reconhecidos e legitimados os direitos sociais do que os direitos civis. Quando são criados programas sociais, como o bolsaescola ou o bolsa-família, eventualmente ocorrem debates e contestações quanto à natureza dos programas, mas não são dirigidas críticas ao fundamento dos mesmos, isto é, o direito à escola, ou o direito à garantia de acesso à alimentação são reconhecidos como legítimos pela maioria da população. 
No entanto, quando são invocados direitos civis básicos, como a presunção de inocência dos acusados de crimes, ou a proibição de castigos cruéis ou degradantes, é comum que os defensores sejam acusados de defender direitos de bandidos (CALDEIRA, 1991).

A indivisibilidade teórica dos direitos proposta em Viena contrasta com a divisibilidade na prática das políticas. Ações destinadas a prover um perfil de direito são desconectadas das que atuam para prover outro perfil. A própria estrutura administrativa contribui para isso, isolando as políticas por Ministério. Mesmo quando há um órgão teoricamente com uma função mais ampla, como a SEDH, ainda pode ocorrer a fragmentação, conforme foi descrito sobre as secretarias para políticas para mulheres e afrodescendentes.

Mesmo entre os militantes de movimentos de defesa de direitos humanos subsistem contradições Há defensores de direitos humanos que lutam pelo uso de penas alternativas e a minimização da repressão penal. No entanto, o movimento de mulheres apoiou a criação de uma lei exatamente no sentido contrário, impedindo o uso de penas alternativas (Lei Maria da Penha).

Por isso, não pode haver surpresa na constatação que o Brasil nos dois mandatos do Presidente Lula não teve uma, mas várias políticas de direitos humanos. Caminharam paralelamente uma política contra a pobreza, uma política para as mulheres, uma política educacional e uma política de reparação de violências da ditadura, entre outras.

A Secretaria Especial dos Direitos Humanos, embora tenha conseguido manter seu status junto à Presidência da República, inclusive com a promessa do Presidente, feita na XI Conferência Nacional de Direitos Humanos, de que futuramente poderia se tornar um ministério, continua exercendo as competências que seriam destinadas ao Ministério da Justiça, tendo pouca ingerência sobre ações dos demais ministérios.

O seu teste de fogo foi a elaboração do III Programa Nacional de Direitos Humanos. O processo de elaboração participativo e seu conteúdo amplo, envolvendo tanto aspectos relativos a direitos civis e 
políticos como econômicos, sociais e culturais indicaria o rumo da formulação de uma política de direitos humanos que incorpora a idéia de interdependência e indivisibilidade entre os diferentes direitos.

Porém, os eventos que sucederam após o lançamento do programa indicam que quando damos um passo à frente, logo retrocedemos dois passos atrás. O resultado apresenta o país real, não os dos debates acadêmicos de direitos humanos.

A política de direitos humanos, neste sentido, não é o resultado da interação de uma comunidade de interesse, como na formulação de Heclo. O que se apresenta não é uma sociedade pluralista, de interesses em disputa, mas a manutenção de forças com poder de veto, seja por clivagens sociais de caráter cultural, como a Igreja Católica, no caso do aborto, seja a divisão entre capital e trabalho, em que os interesses do capital urbano, representado pelas empresas de comunicação, ou rural, representado pelo latifúndio, podem impor sua vontade.

Assim, a legitimidade do conteúdo do III PNDH é aceita enquanto sua força for meramente retórica, reconhecimento de compromissos para o futuro incerto. Porém quando estes entram em choque com interesses dos aliados presentes que garantem sustentação política ao governo, não há espaço para o idealismo, que cede seu lugar ao pragmatismo.

Neste processo a Política de Promoção de Direitos Humanos aparece como o resultado do embate entre os movimentos de direitos humanos e as forças conservadoras, mediado por uma força superior, de caráter quase bonapartista, o Presidente da República, que atua como mediador entre as partes, sustentado por sua imensa popularidade.

Assim, a política existente de promoção aos direitos humanos bem como a estrutura institucional que lhe dá suporte, em termos de secretarias, ministérios e ministros, revela-se frágil e dependente da vontade exclusiva dos ocupantes da Presidência da República, inexistindo garantias de sua continuidade em um próximo governo.

Para que ocorra realmente uma mudança no sentido de criação de uma cultura de respeito aos direitos humanos é necessário combinar as políticas para educação em direitos humanos, uma maior 


\section{DOSSIÊ OS ANOS LULA}

responsabilidade dos meios de comunicação social, que contribuem para a formação da mentalidade brasileira, com um compromisso das autoridades públicas e o fortalecimento e criação de uma unidade mínima de propósitos entre os diversos segmentos que defendem direitos específicos para segmentos da população, tornando-se frágeis na sua fragmentação e diversidade.

Recém estão chegando à idade adulta as novas gerações nascidas sob o regime democrático, que cresceram em um país cheio de desigualdades. Muitos avanços foram conquistados, mas estes são lentos e nem sempre permanentes. A proposição de uma política pública permanente para os direitos humanos que leve à construção de uma sociedade justa continua sendo um desafio a ser alcançado.

Rodrigo Stumpf González é Doutor em Ciência Política. Professor do Programa de Pós-Graduação em Ciência Política da UFRGS.

E-mail: rsg65@terra.com.br

\section{Referências:}

BENTHAM, Jeremy. Anarchial Fallacies: Being an Examination of the Declaration of Rights Issued During the French Revolution. In: BENTHAM, Jeremy; BOWRING, John. Works of Jeremy Bentham. New York: Russell\&Russell, 1962. p. 498-501. v. 2.

BRASIL. Presidência da República. Lei no 9.140, de 04 de dezembro de 1995. Reconhece como mortas pessoas desaparecidas em razão de participação, ou acusação de participação, em atividades políticas, no período de 2 de setembro de 1961 a 15 de agosto de 1979, e dá outras providências. Diário Oficial da União, Brasília, 05 dez. 1995. Disponível em: <https://www.planalto.gov.br/ccivil_03/leis/l9140.htm>. Acesso em: 10 set. 2010.

Disponível

- Programa Nacional de Direitos Humanos. Brasília, 1996. <http://www.planalto.gov.br/publi_04/COLECAO/PRODH.HTM>. Acesso em: 10 set. 2010.

Decreto no 2.193, de 7 de abril de 1997. Dispõe sobre o remanejamento dos cargos em comissão que menciona e altera 
dispositivos do Decreto no 1.796, e 24 de janeiro de 1996, que aprova a Estrutura Regimental do Ministério da Justiça. Diário Oficial da União, Brasília, 08 abr. $1997 . \quad$ Disponível em: <https://www.planalto.gov.br/ccivil_03/decreto/d2193.htm>. Acesso em: 10 set. 2010.

. Presidência da República. Lei no 4.229, de 13 de maio de 2002. Dispõe sobre o Programa Nacional de Direitos Humanos - PNDH, instituído pelo Decreto no 1.904, de 13 de maio de 1996, e dá outras providências. Diário Oficial da União, Brasília, 14 mai. 2002a. Disponível em: <http://www.planalto.gov.br/ccivil_03/decreto/2002/D4229.htm>. Acesso em: 10 set. 2010.

Medida Provisória no 37, de 8 de maio de 2002. Dispõe sobre a estruturação de órgãos, cria cargos em comissão no âmbito do Poder Executivo Federal, e dá outras providências. Diário Oficial da União, Brasília, 09 mai. 2002b. Disponível em: <http://www.planalto.gov.br/ccivil_03/mpv/Antigas_2002/37.htm>. Acesso em: 10 set. 2010.

Presidência da República. Lei no 10.539, de 23 de setembro de 2002. Dispõe sobre a estruturação de órgãos, cria cargos em comissão no âmbito do Poder Executivo Federal, e dá outras providências. Diário Oficial da União, Brasília, 24 mai. 2002c. Disponível em: <http://www.planalto.gov.br/ccivil_03/Leis/2002/L10539.htm>. Acesso em: 10 set. 2010.

Medida Provisória no 103, de 01 de janeiro de 2003. Dispõe sobre a organização da Presidência da República e dos Ministérios, e dá outras providências. Diário Oficial da União, Brasília, 01 jan. 2003a. Disponível em: <http://www.planalto.gov.br/ccivil_03/mpv/Antigas_2003/103.htm>. Acesso em: 10 set. 2010.

Presidência da República. Lei no 10.678, de 23 de maio de 2003. Cria a Secretaria Especial de Políticas de Promoção da Igualdade Racial, da Presidência da República, e dá outras providências. Diário Oficial da União, Brasília, 26 mai. 2003b. Disponível em: <http://www.planalto.gov.br/ccivil_03/Leis/2003/L10.678.htm>. Acesso em: 10 set. 2010.

Decreto no 4.885, de 20 de novembro de 2003. Dispõe sobre a composição, estruturação, competências e funcionamento do Conselho Nacional de Promoção da Igualdade Racial - CNPIR, e dá outras providências. Diário Oficial da União, Brasília, 21 nov. 2003c. Disponível em: <http://www.planalto.gov.br/ccivil_03/decreto/2003/D4885.htm>. Acesso em: 10 set. 2010.

Medida Provisória no 132, de 20 de outubro de 2003. Cria o Programa Bolsa Família e dá outras providências. Diário Oficial da União, 
Brasília, 21 out. 2003d. Disponível em: <http://www.planalto.gov.br/ccivil_03/mpv/Antigas_2003/132.htm>. Acesso em: 10 set. 2010.

- Presidência da República. Lei no 10.683 , de 28 de maio de 2003. Dispõe sobre a organização da Presidência da República e dos Ministérios, e dá outras providências. Diário Oficial da União, Brasília, 29 mai. 2003e. Disponível em: <http://www.planalto.gov.br/ccivil_03/Leis/2003/L10.683.htm>. Acesso em: 10 set. 2010.

. Medida Provisória no 163, de 23 de janeiro de 2004. Altera a Lei no 10.683, de 28 de maio de 2003, que dispõe sobre a organização da Presidência da República e dos Ministérios, e dá outras providências. Diário Oficial da União, Brasília, 23 jan. 2004. Disponível em: <http://www.planalto.gov.br/ccivil_03/_Ato20042006/2004/Mpv/163.htm>. Acesso em: 10 set. 2010.

Decreto no 5.397, de 22 de março de 2005. Dispõe sobre a composição, competência e funcionamento do Conselho Nacional de Combate à Discriminação - CNCD. Diário Oficial da União, Brasília, 23 mar. 2005a. Disponível em: <http://www.planalto.gov.br/ccivil_03/_Ato20042006/2005/Decreto/D5397.htm>. Acesso em: 10 set. 2010.

. Medida Provisória no 259, de 21 de julho de 2005. Altera a Lei no 10.683 , de 28 de maio de 2003 , que dispõe sobre a organização da Presidência da República e dos Ministérios, autoriza a prorrogação de contratos temporários firmados com fundamento no art. 23 da Lei no 10.667, de 14 de maio de 2003, altera o art. 40 da Lei no 8.745, de 9 de dezembro de 1993, e dá outras providências. Diário Oficial da União, Brasília, 22 jul. 2005b. Disponível em: <http://www.planalto.gov.br/ccivil_03/_Ato20042006/2005/Mpv/259.htm >. Acesso em: 10 set. 2010.

Presidência da República. Lei no 11.204, de 5 de dezembro de 2005. Altera a Lei no 10.683 , de 28 de maio de 2003, que dispõe sobre a organização da Presidência da República e dos Ministérios; autoriza a prorrogação de contratos temporários firmados com fundamento no art. 23 da Lei no 10.667, de 14 de maio de 2003; altera o art. 40 da Lei no 8.745, de 9 de dezembro de 1993, e a Lei no 11.182, de 27 de setembro de 2005; e dá outras providências. Diário Oficial da União, Brasília, 06 dez. 2005c. Disponível em: <http://www.planalto.gov.br/ccivil_03/_ato20042006/2005/Lei/L11204.htm>. Acesso em: 10 set. 2010.

- Secretaria Especial dos Direitos Humanos da Presidência da República. Relatórios de Gestão 2006. Brasília: SEDH, 2006. 
- Secretaria Especial dos Direitos Humanos da Presidência da República. Relatórios de Gestão 2007. Brasília: SEDH, 2007a.

Comitê Nacional de Educação em Direitos Humanos. Plano Nacional de Educação em Direitos Humanos: 2007. Brasília: SEDH, 2007b.

- Secretaria Especial dos Direitos Humanos da Presidência da República. Relatórios de Gestão 2008. Brasília: SEDH, 2008a.

- Secretaria Especial dos Direitos Humanos da Presidência da República. $11^{a}$ Conferência nacional dos direitos humanos. Democracia, Desenvolvimento e Direitos Humanos: Superando as Desigualdades. Brasília: SEDH/PR, 2008b.

- Secretaria Especial dos Direitos Humanos da Presidência da República. Relatórios de Gestão 2009. Brasília: SEDH, 2009a.

- Secretaria Especial dos Direitos Humanos da Presidência da República. Programa Nacional de Direitos Humanos (PNDH-3). Brasília: SEDH/PR, 2009b.

. Decreto no 7.037, de 21 de dezembro de 2009. Aprova o Programa Nacional de Direitos Humanos - PNDH-3 e dá outras providências. Diário Oficial da União, Brasília, 22 dez. 2009c. Disponível em: <http://www.planalto.gov.br/ccivil_03/_Ato20072010/2009/Decreto/D7037.htm >. Acesso em: 10 set. 2010.

- Secretaria Especial dos Direitos Humanos da Presidência da República. Programa Nacional de Direitos Humanos (PNDH-3) edição revista. Brasília: SEDH/PR, 2010 a.

. Decreto no 7.177, de 12 de maio de 2010. Altera o Anexo do Decreto no 7.037, de 21 de dezembro de 2009, que aprova o Programa Nacional de Direitos Humanos - PNDH-3. Diário Oficial da União, Brasília, 13 mai. 2010b. Disponível em: <http://www.planalto.gov.br/ccivil_03/_Ato20072010/2010/Decreto/D7177.htm>. Acesso em: 10 set. 2010.

BURKE, Edmund. Reflexiones sobre la Revolución Francesa. In: Textos Políticos. México: Fondo de Cultura, 1884. p. 39-258.

CALDEIRA, Tereza P. Direitos humanos ou 'privilégios de bandidos'? Desventuras da democratização brasileira. Novos Estudos CEBRAP, São Paulo, n. 30, p. 162-174, jul. 1991.

CANÇADO TRINDADE, Antônio Augusto. Tratado de Direito Internacional dos Direitos Humanos. Porto Alegre: Sergio Fabris Ed., 1997. 


\section{DOSSIÊ OS ANOS LULA}

CNBB. Confederação Nacional dos Bispos do Brasil. Declaração da $48^{a}$ Assembléia Geral da CNBB sobre o 30 Programa Nacional de Direitos Humanos (PNDH - 3). Brasília, maio de 2010. Disponível em: <http://www.cnbbne4.org.br/pub/publicacoes/48agpndh31.pdf>.

Acesso em 10 set. 2010.

DYE, Thomas. Understanding Public Policies. Englewood Cliffs: Prentice Hall, 1987.

GONZÁLEZ, Rodrigo Stumpf. Direitos Humanos e Democracia na Transição Brasileira: CNBB, OAB e Anistia Internacional. 1994. 230 f. Dissertação (Mestrado em Ciência Política) - Programa de Pósgraduação em Ciência Política, Universidade Federal do Rio Grande do Sul, [1994].

Direitos Humanos Hoje: Heranças de Transições Inconclusas. In: KEIL, Ivete; VIOLA, Sólon; ALBUQUERQUE, Paulo (Orgs.). Direitos Humanos: alternativas de justiça social na América Latina. São Leopoldo: Ed. Unisinos, 2002. p. 143-158.

A atuação da Ordem dos Advogados do Brasil na defesa dos direitos humanos e da democracia: análise histórica. Estudos jurídicos, São Leopoldo, v. 38, n. 3, p. 59-64, set.-dez. 2005.

A Retórica dos Direitos Humanos. In: ROCHA, Leonel Severo; STRECK, Lenio (Orgs.). Constituição, Sistemas Sociais e Hermenêutica. 3. ed. Porto Alegre: Livraria do Advogado, 2007. p. 183-202.

- Políticas de promoção de direitos humanos no Brasil: descontinuidades e desafios. In: STRECK, Lenio; MORAIS, José Bolzan de (Orgs.). Constituição, sistemas sociais e hermenêutica. 4. ed. São Leopoldo: Unisinos, 2008. p. 183-202.

HECLO, Hugh. Issue Networks and the Executive Establishment. In: KING, Anthony (Ed.). The New American Political System. Washington D.C.: American Enterprise Institute, 1978. p. 87-124.

INESC. A política de Direitos Humanos no Governo Lula. Brasília: INESC, 2005. (Nota Técnica n. 99).

MESQUITA NETO, Paulo de. O papel do governo federal no controle da violência: o Programa Nacional de Direitos Humanos, 1995-1997. In: AMARAL Jr., Alberto do; PERRONE-MOISÉS, Claudia (Orgs.). $O$ Cinqüentenário da Declaração Universal dos Direitos do Homem. São Paulo: Edusp, 1999. p. 353-375.

OLIVEIRA, Isabel Ribeiro de. Cidadania e política de direitos humanos no Brasil. Contemporaneidade e Educação, Rio de Janeiro, v. 5, n. 8, p. 5675, 2000. 
ONU. Declaração e Programa de Ação de Viena. Viena: ONU, 1993.

PINHEIRO, Paulo Sérgio; MESQUITA NETO, Paulo de. Programa Nacional de Direitos Humanos: avaliação do primeiro ano e perspectivas. Estudos Avançados, São Paulo, v. 11, n. 30, p. 117-134, mai.-ago. 1997.

ROUSSEAU, Jean Jacques. O contrato social e outros escritos. São Paulo: Cultrix, 1989.

SILVA, Luis Inácio Lula da. Carta ao Povo Brasileiro. 22 jun. 2002. Disponível em: <http://www2.fpa.org.br/carta-ao-povo-brasileiro-porluiz-inacio-lula-da-silva>. Acesso em: 28 ago. 2010.

SINGER, André. Entrevista do Porta Voz André Singer. 12 jul. 2005. Disponível em: <http://www.radiobras.gov.br/integras/2005/integra_12072005_4.htm $>$. Acesso em: 20 nov. 2010. 